\title{
HEMIBALLISMUS AFTER HEMORRHAGIC STROKE
}

\author{
Vlad Claudiu Stefanescu ${ }^{1}$, Irene Davidescu ${ }^{1,2}$, Ioan Buraga ${ }^{1,2}$, \\ Bogdan Ovidiu Popescu ${ }^{1,2,3}$ \\ ${ }^{1}$ Neurology Department, „Colentina“ Clinical Hospital, Bucharest \\ ${ }^{2}$ „Carol Davila“, University of Medicine and Pharmacy, Bucharest \\ ${ }^{3}$ Laboratory of Molecular Medicine and Neuroscience, \\ "Victor Babes" National Institute of Pathology, Bucharest
}

\section{INTRODUCTION}

Ischemic or hemorrhagic stroke may be accompanied by movement disorders (1), either hyperkinetic or hypokinetic. Hyperkinetic movement disorders after stroke comprise dystonia (2-4), chorea with or without hemiballismus (5), tremor (6), parkinsonism (7), segmental or focal myoclonus, athetosis, pseudathetosis, and asterixis (8).

Hemiballismus is a movement disorder characterized by involuntary, arrythmic, and large amplitude excursion of a limb, usually from a proximal joint, witn an element of rotation (9). Ballismus is explainable with lesions in the subthalamic nuclei, cerebral cortex, corpus striatum, thalamus and brainstem. (10)

The frequency of post-stroke abnormal movements is unclear, the prevalence in a swiss registry being $1 \%$ with an incidence of $0.08 \%$ per year (8). Of them, hemichorea-hemiballismus is the most common, while dystonia is the next most common disorder (11).

\section{CASE REPORT}

We present the case of a 72 year-old man, with a history of prosthate hypertrophy, osteoporosis, kidney stones, compression fractures at T12-L2 level, smoking and alcohol consumption.. The patient had been admitted in 2013 in the National Geriatric Institute "Dr. Ana Aslan", and was recommended treatment with Aspirin $75 \mathrm{mg} /$ day, Metoprolol
$50 \mathrm{mg} /$ day, Carbamazepin $400 \mathrm{mg} /$ day, Simvastatin $20 \mathrm{mg} /$ day, Sermion $60 \mathrm{mg} /$ day, but the patient selfinterrupted the medication.

He presented involuntary movements of his upper left limb for three days before he presented to the general practitioner's office, who referred him to our Department for further clinical investigation.

General examination revealed bilateral gonarthrosis, normal pulmonary and cardiac findings, $\mathrm{BP}=130 / 90 \mathrm{~mm} \mathrm{Hg}, \mathrm{HR}=78 \mathrm{bpm}$, anxious state.

Neurologic examination revealed ballismus of the upper left limb, hypertonia of the left limb, without any other further neurologic finding.

We performed a brain CT which showed a hyperdense lesion at the level of the right cerebral peduncule - interpreted as a cavernoma, or a hemorrhagic stroke; leukoaraiosis and cerebral atrophy. (Fig. 1)

Because the result was inconclusive, we performed a cerebral MRI, describing a lesion of approximateley $1 \mathrm{~cm}$ in diameter, $\mathrm{T} 1$ - isointense, $\mathrm{T} 2$, FLAIR - hyperintense, with restriction on DWI sequence, and topographically corresponds to the site of the CT lesion, multiple areas suggesting leukoaraiosis, cerebral atrophy, lacunes (Fig. 2).

Laboratory findings:

The final diagnosis was hemorrhagic stroke at the level of the subthalamic nucleus, with contralateral associated hemiballismus, cerebral atrophy, Compression frectures at T12-L2 level, prosthate hypertrophy. 


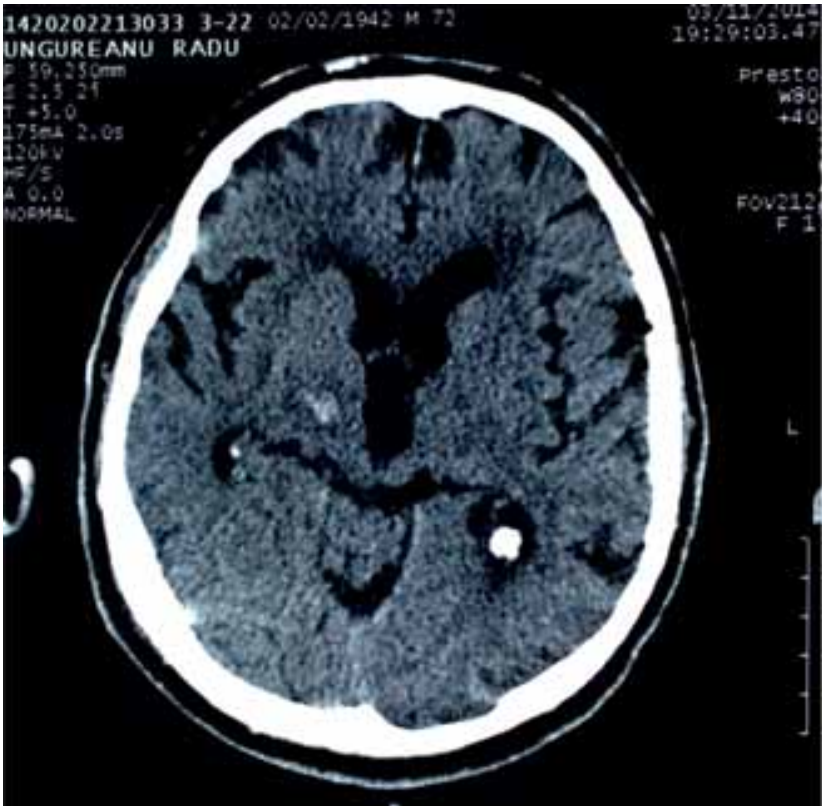

FIGURE 1. Brain CT showing a hyperdense lesion at the level of the right subthalamic nucleus

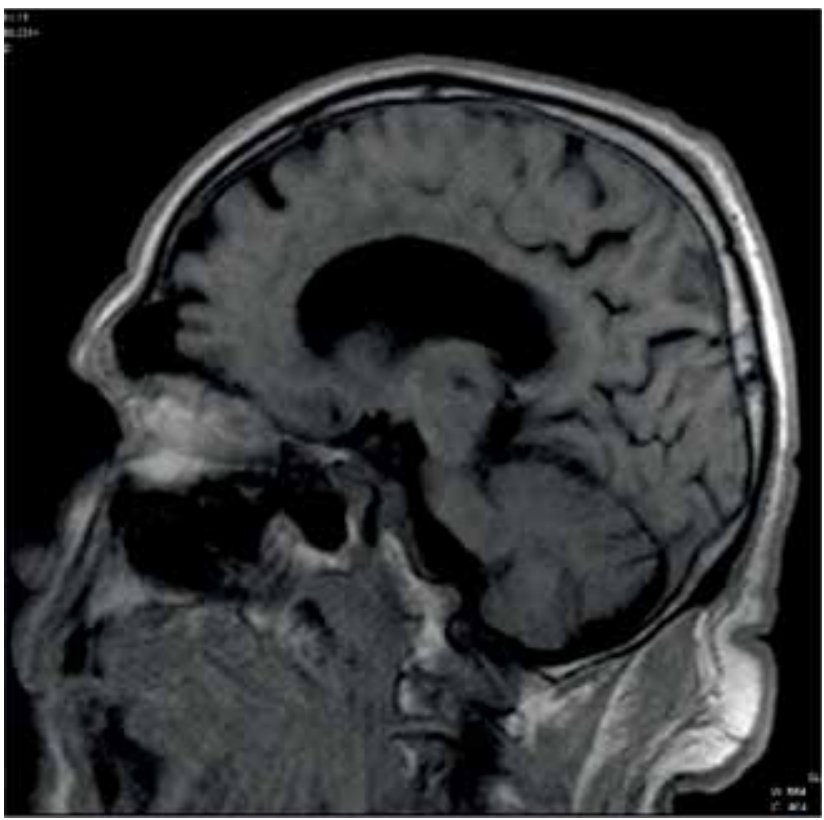

FIGURE 2. Coronal T1-weighed image taken several days after the initial CT presents a hypointense area at the level of the right subthalamic nucleus
The outcome was favourable, under iv macromolecular solutions, antihypertensive medication.

\section{DISCUSSION}

Usually ischemic stroke manifests as focal neurologic deficits. Hemorrhagic stroke has an onset with headache, vomiting, seizures, nuchal rigidity, and focal neurologic deficit (12). However small haemorrhages may be clinically silent or mimic an ischemic stroke.

Several risk factors for hemorrhagic stroke have been noted, such as hypertension, arterio-venous malformations, ruptured sacular aneurysm, cavernous angioma, trauma, hematologic disorders, intratumoral hemorrhage, septic embolism, amyloidosis (12).

The patient had a hystory of alcohol and tobacco intake, risk factors associated with cerebral amyloidosis. Also, he did not follow any medication that was prescribed by the gerontologist.

The particularity of the case was the subacute onset with just involuntary movements of the upper left limb. He did not present any of the typical findings of a cerebral hemorrhage. Also he had a normal blood pressure.

The initial brain CT failed to provide detailed information about the lesion. It was first interpreted as a cavernous angioma, so a brain MRI had to be performed, which did not emphasize any arterial malformations. Also the MRI did show the retraction of the hemorrhagic collection.

Further investigation should have included a cerebral angiography, but it could not be performed on technical grounds.

In the end, the patient was diagnosed with hemorrhagic stroke at the level of the subthalamic nucleus, with contralateral associated hemiballismus, probably in context of a cerebral amyloidosis, the patient having an important history of alcohol and cigarette intake.

\section{REFERENCES}

1. Handley A., Medcalf P., Hellier K., Dutta D. Movement disorders after hemorrhagic stroke. Age Ageing. 2009; 38:260-266. doi: 10.1093/ageing/afp020

2. Chuang C., Fahn S., Frucht S.J. The natural history and treatment of acquired hemidystonia: report of 33 cases and review of the literature. J Neurol Neurosurg Psychiatry 2002; 72; 59-67

3. Fahn S. Concept and classification of dystonia. In: Fahn S, Marsden CD, Calne DB, eds. Advances in Neurology, Dystonia. New York: Raven Press, 1988; 58.

4. Krystkowiak P., Martinat P., Defebvre L. et al. Dystonia after striatopallidal and thalamic stroke: clinicoradiological correlations and pathophysiological mechanisms. J NeurolNeurosurg Psychiatry 1998; 65: 703-8

5. Bhatia K.P., Marsden C.D. The behavioural and motor consequences of focal lesions of the basal ganglia in man. Brain 1994; 117: 859-76.

6. Lehericy S., Grand S., Pollak P. et al. Clinical characteristics and topography of lesions in movement disorders due to thalamic lesions Neurology 2001; 57:1055-66. 
7. Fitzgerald P.M., Jankovic J. Lower body Parkinsonism: evidence for a vascular aetiology. MovDisord 1989; 4: 249-60

8. Alarcon F., Zijlmans J.C., Duenas G., Cevallos N. Post-stroke movement disorders: report of 56 patients. J Neurol Neurosurg Psychiatry 2004; 75:1568-74

9. Fahn S. Phenomenology of movement disorders. In: Fahn S, Marsden, Jankovic J, eds. 7th Annual Course:A Comprehensive Review of Movement Disorders for the Clinical Practitioner. New York: Columbia University, 1997; 3-61

10. Rahmani S.H., Shams Vahdati S., Ahmadi S., Tajlil A. Ballismus as sign of transitional ischemic attack. Ann Saudi Med 2012 July 1.doi: 10.5144/0256-4947.2012.01.7.1515
11. Ghika-Schmid F., Ghika J., Regli F., Bogousslavsky J. Hyperkinetic movement disorders during and after acute stroke: the Lausanne Stroke Registry. J Neurol Sci 1997; 146:109-16

12. Liebeskind D.S. Hemorrhagic stroke [Internet]. 1994 [updated 2014 May 27; cited 2014 Jul 6]. Available from: http://emedicine.medscape. com/article/1916662-overview 